\title{
Validation of sensor for postoperative positioning with intraocular gas
}

\author{
This article was published in the following Dove Press journal: \\ Clinical Ophthalmology \\ 25 May 2016 \\ Number of times this article has been viewed
}

\author{
Frank L Brodie' \\ Kelly Y Woo ${ }^{2}$ \\ Ashwin Balakrishna ${ }^{2}$ \\ Hyuck Choo ${ }^{2}$ \\ Robert H Grubbs² \\ 'Department of Ophthalmology, \\ University of California San Francisco, \\ San Francisco, ${ }^{2}$ Department of Medical \\ Engineering, California Institute of \\ Technology, Pasadena, CA, USA
}

Purpose: Surgical repair of retinal attachment or macular hole frequently requires intraocular gas. This necessitates specific postoperative positioning to improve outcomes and avoid complications. However, patients struggle with correct positioning. We have developed a novel sensor to detect the position of the gas bubble in the eye and provide feedback to patients in real time. In this paper, we determine the specificity and sensitivity of our sensor in vitro using a model eye.

Methods: We assessed the reliability of our sensor to detect when a gas bubble has deviated off a model retinal break in a model eye. Various bubble sizes representing the intraocular kinetics of sulfur hexafluoride gas and varying degrees of deviation from the correct position were tested using the sensor attached to a mannequin head with a model eye.

Results: We recorded 36 data points. The sensor acted appropriately in $33(91.7 \%)$ of them. The sensor triggered the alarm every time the bubble deviated off the break $(n=15$, sensitivity $=100 \%)$. However, it triggered the alarm (falsely) 3/21 times when the bubble was correctly positioned over the retinal break ( specificity $=86 \%$ ).

Conclusion: Our device shows excellent sensitivity (100\%) and specificity (86\%) in detecting whether intraocular gas is tamponading a retinal break in a model eye.

Keywords: postoperative positioning, intraocular gas, vitrectomy, retinal detachment, macular hole, pneumatic retinopexy

\section{Introduction}

The use of intraocular gas for repair of retinal detachment and macular hole is a major component of vitreoretinal surgery and pneumatic retinopexy. Postoperatively, the patient is positioned so that the gas bubble is in apposition to the retinal break(s). This requires specific orientation of the head to ensure tamponade of all retinal breaks.

The importance and duration of postoperative positioning have been the subject of numerous studies and analyses. ${ }^{1-8}$ While there is no consensus on duration needed and the ultimate impact of positioning on preventing re-detachment, a recent survey of retinal specialists showed that over $90 \%$ of them instruct their patients to position postoperatively. ${ }^{9}$ Positioning is important not only for achieving retinal reattachment but also for preventing postoperative complications such as cataract and glaucoma. ${ }^{10}$ In spite of the surgeon's instructions regarding the importance of proper head positioning after injection of intraocular gas, many patients are not compliant with the prescribed regimen. A study comparing the patients' perceived adherence to positioning and actual recorded head position highlighted this challenge. ${ }^{5}$ In this study, the authors found that the patients overestimated the time spent in correct positioning by twofold. In another study, researchers used gyro-accelerometers to continuously monitor head position. ${ }^{5}$ Although the correlation between the device readings and the actual bubble positions in the eye was never verified, the authors found that during the first 24 hours,
Correspondence: Frank L Brodie

Department of Ophthalmology,

University of California San Francisco,

10 Koret Way, San Francisco,

CA 94143 , USA

$\mathrm{Tel}+\mathrm{I} 4157102410$

Fax + I 4154760336

Email frank.brodie@ucsf.edu
Clinical Ophthalmology 2016:10 955-960

(c) (1) (8) ( ) 2016 Brodie et al. This work is published and licensed by Dove Medical Press Limited. The full terms of this license are avalable at https://www.dovepress.com/terms.php cc. hereby accept the Terms. Non-commercial uses of the work are permitted without any further permisision from Dove Medical Press Limited, provided the work is properly atributed. For peminsion for commercial use of this work, please see paragraphs 4.2 and 5 of our Terms (htpps://www.dovepress. com/terms.php). 
the average time spent in the correct head position was only $18 \% .{ }^{11}$ In addition, a large study of 145 patients with direct observation of the patients four times daily to assess positioning compliance showed that only one-third of the patients positioned correctly. ${ }^{12}$ These studies tracked compliance either intermittently through observation or continuously through a large worn electronic sensor. To date, no study has developed a device with a clinical potential for either monitoring or providing feedback to patients. Additionally, no study to date has validated the sensor against actual bubble position relative to the retinal break, instead, relying on head angle as a surrogate.

To address both compliance and correct head positioning in patients with intraocular gas bubbles, we have engineered a small, simple, and low-cost electronic sensor and alarm to provide real-time monitoring of patients' head positioning. The sensor would be worn externally on the side of the patients' head. In this study, we test our external positioning sensor in three dimensions against a model eye with a modeled retinal break and gas bubbles of varying sizes to assess the fidelity of the sensor to intraocular gas position. Specifically, does the sensor correctly sound the alarm when the intraocular bubble is positioned off the retinal break (sensitivity)? Does it cause false alarms when the bubble is actually correctly positioned (specificity)?

\section{Methods}

The experiment was designed to assess sensor alarm fidelity to bubble position in a model eye. Our test conditions mimicked gas in the eye after pneumatic retinopexy, with pure sulfur hexafluoride $\left(\mathrm{SF}_{6}\right)$ gas first expanding then dissipating. We modeled the volume of an injected $100 \% \mathrm{SF}_{6}$ intraocular gas bubble on days 1,3 , and 5 postoperatively. One hundred percent $\mathrm{SF}_{6}$ gas initially doubles in volume in the first 24 hours after injection and is then resorbed with a predictable half-life. Days 1, 3, and 5 of gas volume (assuming a $0.5 \mathrm{~cm}^{3}$ initial injection) are $1,0.57$, and $0.32 \mathrm{~cm}^{3}$, respectively. ${ }^{13}$

This in vitro study did not use any biological specimens and as such was exempt from review by the Institutional Review Board.

\section{Model eye}

The radius of curvature of the posterior segment of the human eye is $12 \mathrm{~mm}$. To replicate these conditions, a glass sphere with a radius of $12 \mathrm{~mm}$ was used. However, this yielded a greater volume $\left(6.44 \mathrm{~cm}^{3}\right)$ than the human vitreous $\left(4 \mathrm{~cm}^{3}\right)$. To compensate for this increase in volume, the gas volumes used in the model eye were proportionally increased from the values described earlier. To replicate the conditions of a postoperative day 1 gas bubble, $1.61 \mathrm{~cm}^{3}$ of air and $4.83 \mathrm{~cm}^{3}$ of water were placed in the model eye. The day 3 model eye had $0.91 \mathrm{~cm}^{3}$ and $5.53 \mathrm{~cm}^{3}$ air and water, respectively. The day 5 model eye had $0.52 \mathrm{~cm}^{3}$ and $5.92 \mathrm{~cm}^{3}$ air and water, respectively. A $2 \mathrm{~mm}$ area on the globe was marked to identify the location of the retinal break.

\section{Positioning sensor}

The sensor consists of a $10 \mathrm{~mm}$ radius three-dimensional printed hollow sphere (Polylactic acid [PLA] transparent $2.85 \mathrm{~mm}$ diameter filament, Ultimaker, Geldermalsen, the Netherlands) containing $3.85 \mathrm{~cm}^{3}$ of saturated sodium chloride solution and $0.34 \mathrm{cc}$ air bubble. This bubble size was chosen so it would be proportional to $\mathrm{SF}_{6}$ bubble size on day 5 in the eye (the smallest bubble used in this experiment). This was done to provide for maximum sensitivity of the sensor.

Two electrodes were placed at the opposite ends of the sphere. One of these electrodes was attached to a power source and the other to a simple circuit with an alarm light emitting diode (LED). When the gas bubble was not occluding one of the electrodes, the circuit would close (or connect) and the alarm would trigger (Figure 1A). However, when the air bubble covered an electrode, the circuit remained open (or disconnected) and the alarm did not trigger (Figure 1B), indicating the desired head position.

\section{Experiment}

A styrofoam head was used to hold the model eye in the orbit, and the positioning sensor was affixed to the ear of the styrofoam head. The retinal break was marked at 12 o'clock for head-up positioning and at the macula for face-down positioning. The sensor-electrode axis was aligned with the marked retinal break. Three types of deviation from the correct position were tested: 1) axial rotation, 2) anterior elevation (looking up) from a head-down position, and 3) lateral (head tilt) from a neutral position (Figures 2 and 3 ). Each deviation was tested at the angles of 20,30,45, and 58 degrees as determined by the digital angle gauge (Wixey Company, Sanibel, FL, USA).

In each position, two photos were taken to assess the intraocular gas position relative to the break in the model eye and to verify the corresponding status of the alarm light on the sensor. These were all repeated using the days 1, 3, and 5 intraocular gas bubbles in the model eye as described earlier.

\section{Results}

A total of 36 measurements were taken. Three variations of incorrect positioning were measured at progressive 

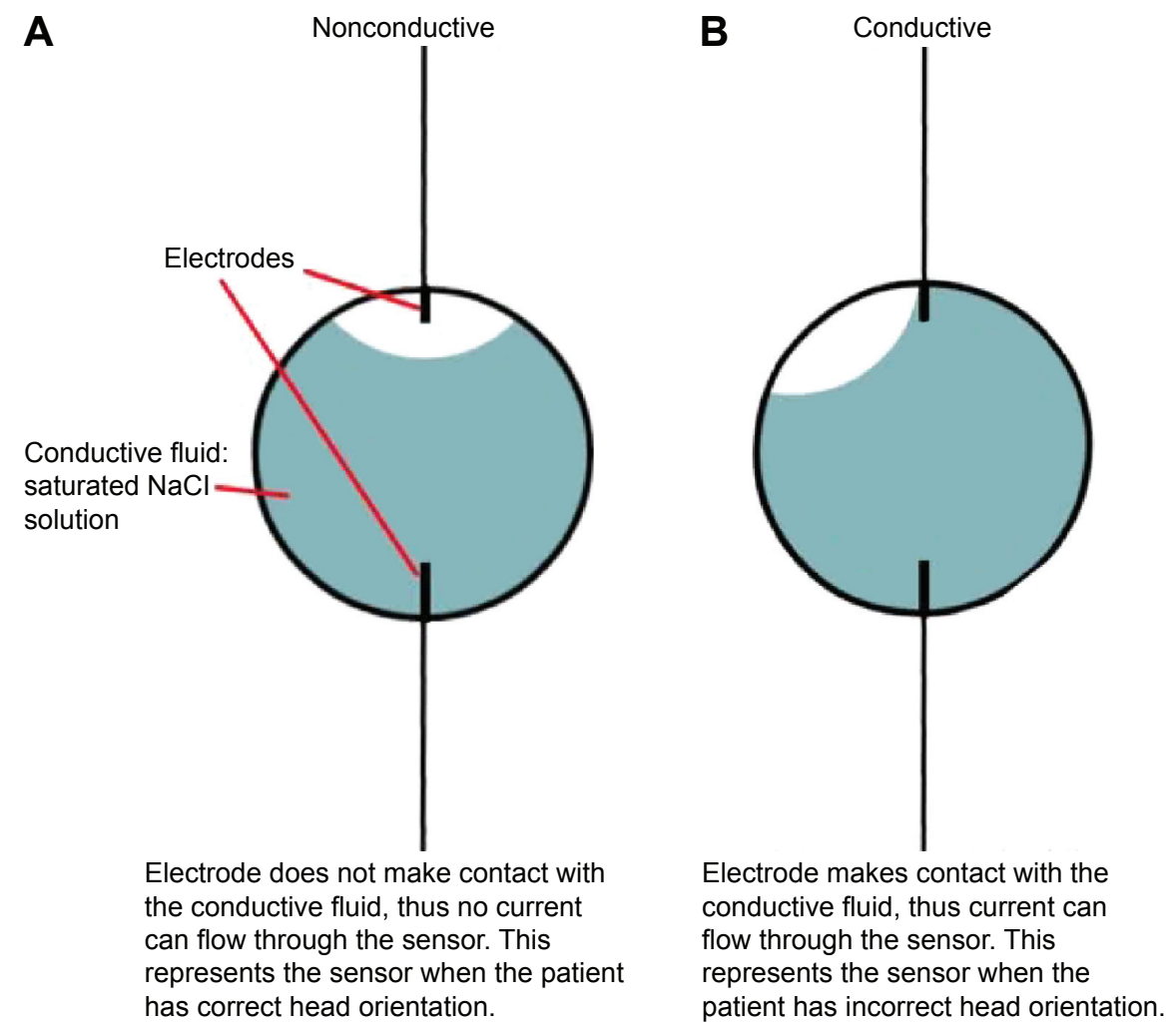

Figure I (A) Schematic of sensor in correct head position with the bubble occluding the electrode, thereby breaking the circuit. (B) Schematic of sensor with incorrect head position. The bubble is no longer occluding the electrode and the circuit is thereby complete, causing alarm to sound.

degrees of deviation from the correct position (Figures 2 and 3). Each position was tested using three different sizes of intraocular gas bubbles, which represented the kinetics of $100 \% \mathrm{SF}_{6}$ gas in the human eye. The position of the bubble relative to the retinal break and the alarm status were both recorded. These data and agreement between the sensor alarm and the intraocular gas bubble position are shown in Figure 4.

Both the sensor and the intraocular gas bubble behaved the same way across all three types of deviation from correct positioning (axial, tilt, and looking up).

Across all three gas bubble sizes (days 1, 3, and 5), the intraocular bubble remained on the model retinal break at 20 and 30 degrees of deviation, and the sensor, appropriately, did not sound the alarm. Similarly, across all three bubble sizes, the intraocular bubble was off the break at 58 degrees of deviation and the sensor, appropriately, sounded the alarm.

Discrepancy between the sensor and the bubble position in the model eye occurred with the day 1 (largest) intraocular bubble at 45 degrees of deviation: the sensor alarm triggered, but the intraocular bubble was still covering the break. This is not surprising given that the smallest bubble (commensurate with day 5 gas volume) was chosen for the sensor, but on day 1 the intraocular bubble was significantly larger ( $1.61 \mathrm{~cm}^{3}$ of gas vs $0.52 \mathrm{~cm}^{3}$ of gas), so it was able to cover the break despite a large deviation from correct position. This difference between the small bubble in our sensor and the larger bubble in the model eye led to an overly sensitive sensor for day 1 measurements. However, as the intraocular bubble became smaller on days 3 and 5, it no longer covered the retinal break and the sensor continued to sound the alarm, now appropriately.

In summary, of the 36 recorded data points, the sensor acted appropriately in $33(91.7 \%)$ of them. The sensor sounded the alarm every time the bubble was off the break $(\mathrm{n}=15$, sensitivity $=100 \%)$. However, it sounded the alarm (falsely) 3/21 times even when the bubble was correctly positioned over the retinal break ( specificity $=86 \%$ ).

\section{Discussion}

In this experiment, we showed good fidelity between the sensor sounding the alarm for incorrect positioning when the intraocular bubble in the model eye did not tamponade the retinal break. Given the changing intraocular bubble size over time, a tradeoff between sensitivity and specificity was required in the design of the sensor. This is observed in the results, as the sensor had $100 \%$ sensitivity but only $86 \%$ specificity due to 

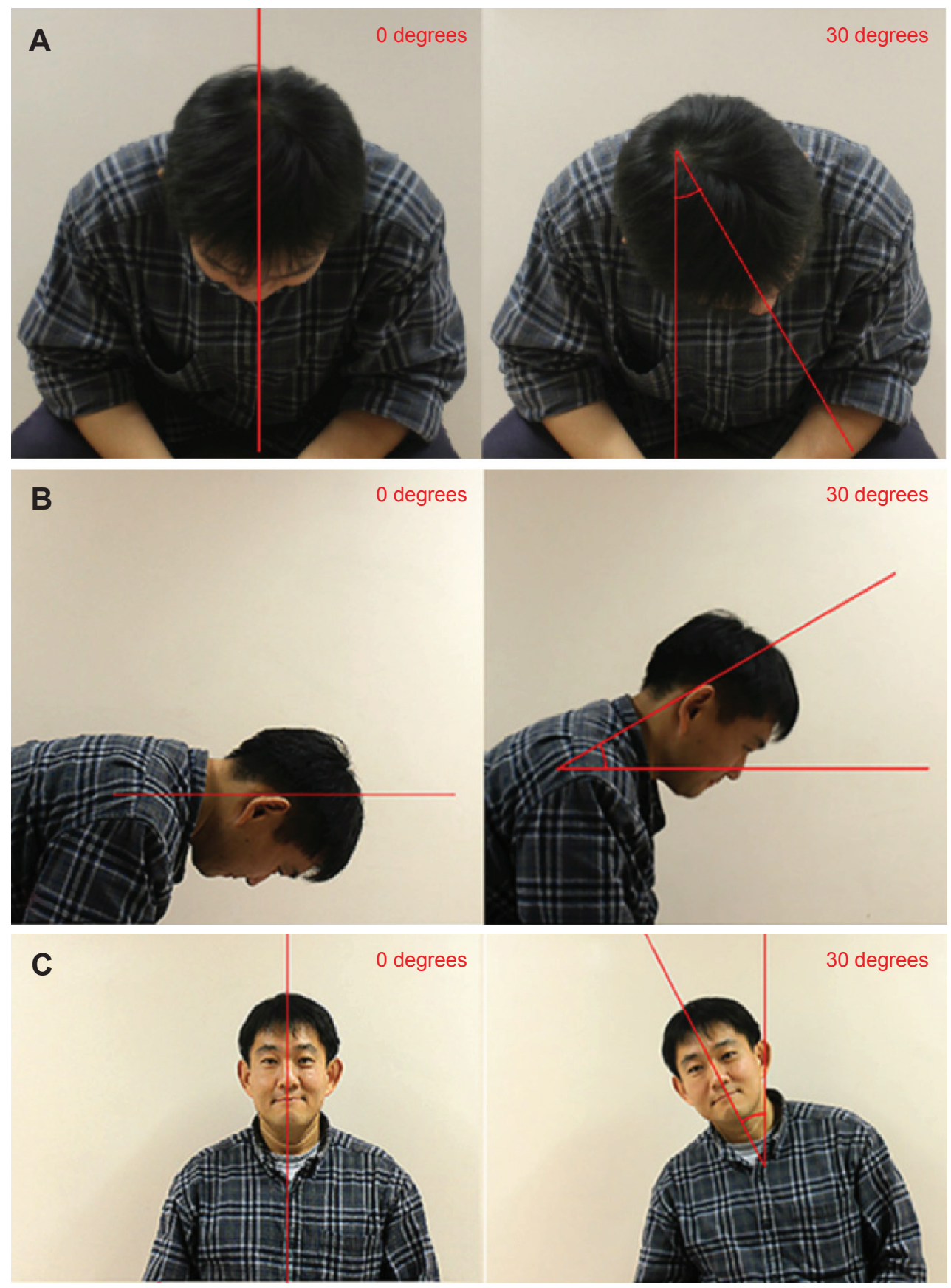

Figure 2 Positioning on human model.

Notes: (A) Axial rotation. (B) Anterior elevation (looking up) from a head-down position. (C) Lateral (head tilt) from a neutral position: 20,45 , and 58 degrees of deviation not pictured. Consent was obtained from the subject for use of the photography.

"false alarms". These occurred when the intraocular bubble was at its maximum (and thereby able to cover the retinal break even at 45 degrees of deviation). However, as the bubble shrank on subsequent days, the break was no longer covered and the sensor sounded the alarm correctly.

Vitrectomy with an intraocular gas bubble is increasingly used to treat the vast majority of retinal detachments..$^{14,15}$ Proper positioning after surgery is important not only in surgical success but also for avoiding complications, including gas-induced cataract formation. ${ }^{16} \mathrm{~A}$ recent study shows that correct postoperative positioning dramatically reduces the incidence of postoperative cataract. ${ }^{17}$

However, proper positioning remains challenging for patients, with the majority overestimating the time spent in the correct position and ultimately not positioning correctly for much of the postoperative period. ${ }^{5,11,12}$ Previous studies 

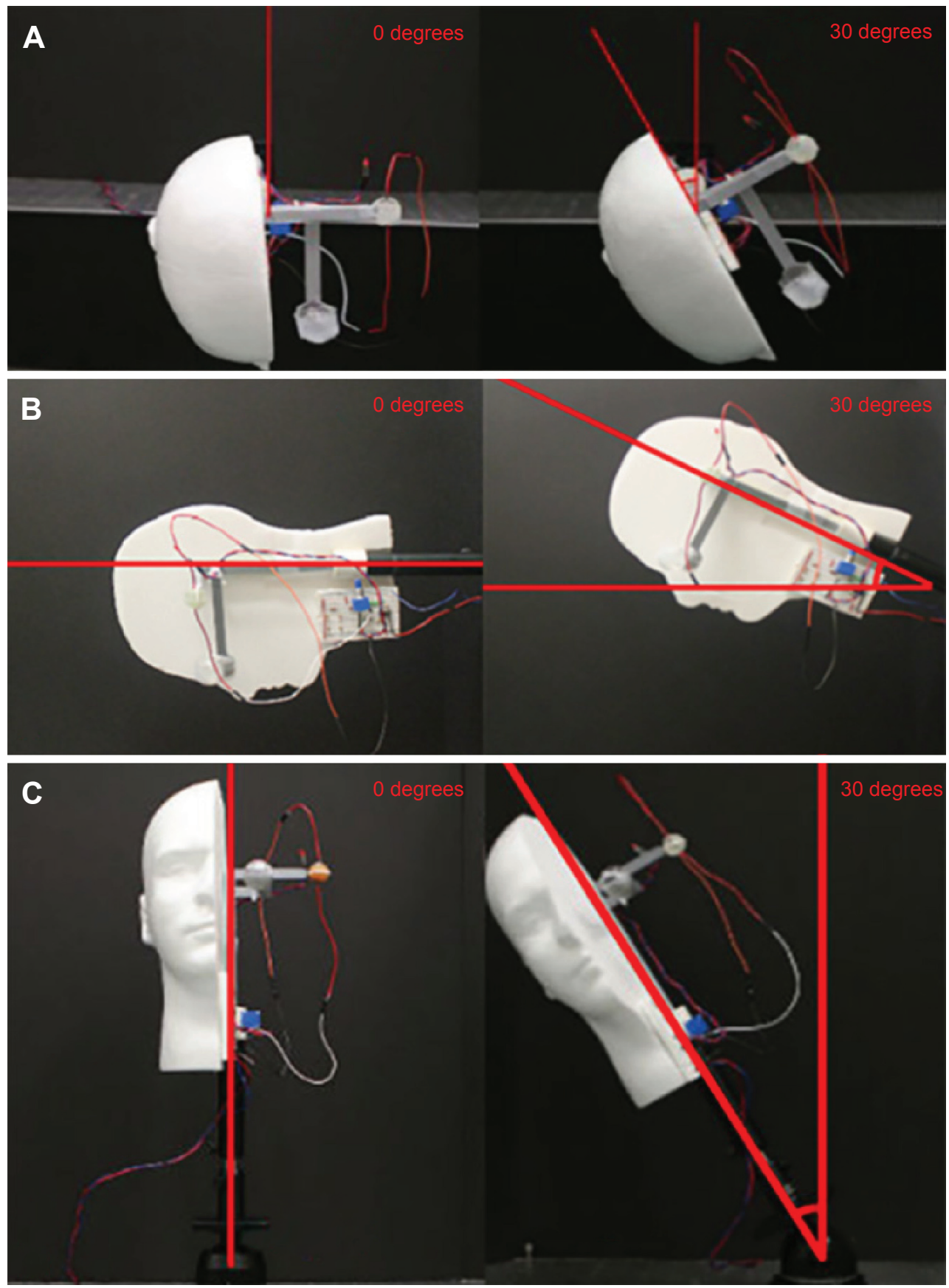

Figure 3 Positioning using styrofoam model head equipped with model eye and positioning sensor located at the ear to mimic how it would be worn by the patient. Notes: (A) Axial rotation. (B) Anterior elevation (looking up) from a head-down position. (C) Lateral (head tilt) from a neutral position: 20, 45 , and 58 degrees of deviation not pictured.

have not validated their tracking devices against intraocular bubble position and have not accounted for the dynamics of changing bubble size.,11 Our device will allow ongoing tracking of positioning and these data can further elucidate the relationship between quality and quantity of positioning and the risk of re-detachment. Additionally, our device is able to provide real-time feedback to patients to assist in correct positioning, and could even wake them from sleep (when most of the incorrect positioning was observed). ${ }^{11}$ Additionally, simple modifications to our device will allow recording of the amount of time the patients spent in the proper position.

Having shown that our sensor can accurately detect when the intraocular gas bubble is out of position in vitro, we plan to proceed with in vivo testing of sensor fidelity, and see if providing real-time feedback to patients affects positioning compliance and outcomes in the postoperative period. 


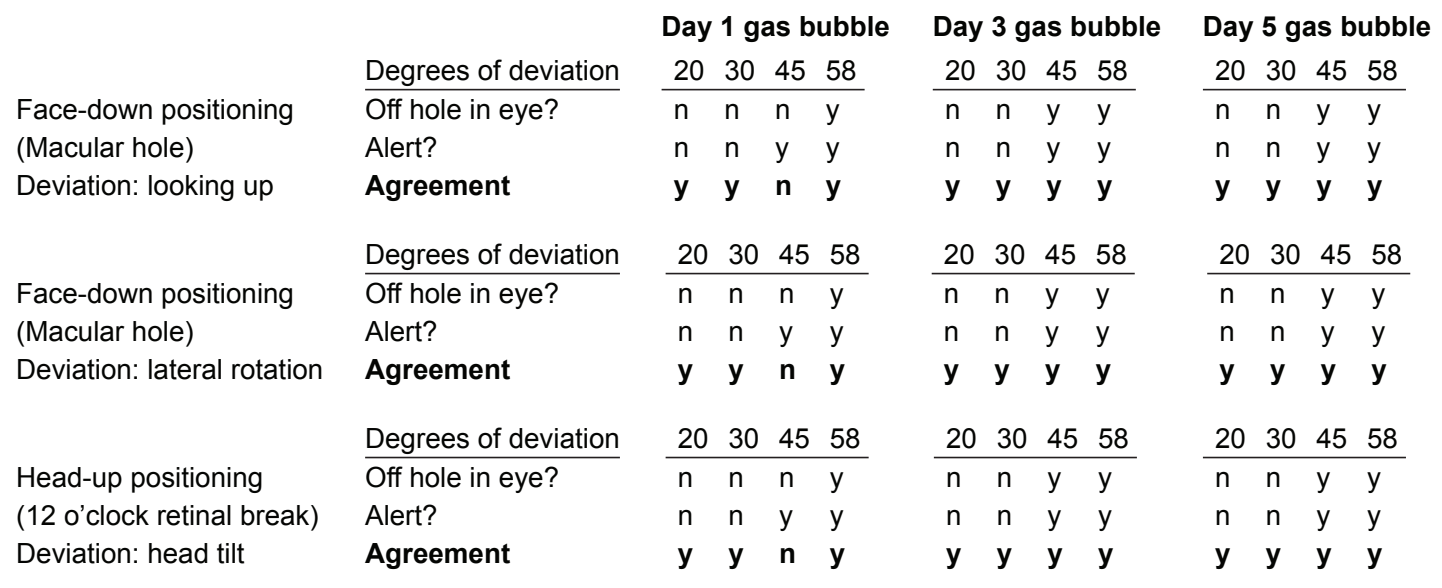

Figure 4 Experimental data.

\section{Acknowledgment}

Research support was provided by the That Man May See and Research to Prevent Blindness.

\section{Disclosure}

A patent has been filed by California Institute of Technology on behalf of the authors; as such there is a potential for financial benefit if this concept is commercialized. The authors report no other conflicts of interest in this work.

\section{References}

1. Solebo AL, Lange CA, Bunce C, Bainbridge JW. Face-down positioning or posturing after macular hole surgery. In: The Cochrane Collaboration, ed. Cochrane Database of Systematic Reviews. Chichester, UK: John Wiley \& Sons, Ltd; 2011. Available from: http://doi.wiley. com/10.1002/14651858.CD008228.pub2. Accessed May 11, 2015.

2. Chen X, Yan Y, Hong L, Zhu L. A comparison of strict face-down positioning with adjustable positioning after pars plana vitrectomy and gas tamponade for rhegmatogenous retinal detachment. Retina. 2015;35(5):892-898.

3. Guillaubey A, Malvitte L, Lafontaine PO, et al. Comparison of face-down and seated position after idiopathic macular hole surgery: a randomized clinical trial. Am J Ophthalmol. 2008;146(1): 128-134.e1.

4. Forsaa VA, Raeder S, Hashemi LT, Krohn J. Short-term postoperative non-supine positioning versus strict face-down positioning in macular hole surgery. Acta Ophthalmol (Copenh). 2013;91(6): 547-551.

5. Verma D, Jalabi MW, Watts WG, Naylor G. Evaluation of posturing in macular hole surgery. Eye Lond Engl. 2002;16(6):701-704.

6. Tadayoni R, Vicaut E, Devin F, et al. A randomized controlled trial of alleviated positioning after small macular hole surgery. Ophthalmology. 2011;118(1):150-155.

Clinical Ophthalmology

\section{Publish your work in this journal}

Clinical Ophthalmology is an international, peer-reviewed journal covering all subspecialties within ophthalmology. Key topics include: Optometry; Visual science; Pharmacology and drug therapy in eye diseases; Basic Sciences; Primary and Secondary eye care; Patient Safety and Quality of Care Improvements. This journal is indexed on Submit your manuscript here: http://www.dovepress.com/clinical-ophthalmology-journal
7. Lange CAK, Membrey L, Ahmad N, et al. Pilot randomised controlled trial of face-down positioning following macular hole surgery. Eye (Lond). 2012;26(2):272-277.

8. Iezzi R, Kapoor KG. No face-down positioning and broad internal limiting membrane peeling in the surgical repair of idiopathic macular holes. Ophthalmology. 2013;120(10):1998-2003.

9. Stone TW, ed. ASRS 2015 Preferences and Trends Membership Survey. Chicago, IL. American Society of Retina Specialists; 2015.

10. Mohamed S, Lai TY. Intraocular gas in vitreoretinal surgery. $H K$ J Ophthalmol. 2010;14(1):8-13.

11. Leitritz MA, Ziemssen F, Voykov B, Bartz-Schmidt KU. Usability of a gravity- and tilt-compensated sensor with data logging function to measure posturing compliance in patients after macular hole surgery: a pilot study. Graefes Arch Clin Exp Ophthalmol. 2014;252(5):739-744.

12. Yui Seno M, Shimada Y, Mizuguchi T, Tanikawa A, Horiguchi M. Compliance with the face-down positioning after vitrectomy and gas tamponade for rhegmatogenous retinal detachments. Retina. 2015; 35(7):1436-1440.

13. Thompson JT. Kinetics of intraocular gases. Disappearance of air, sulfur hexafluoride, and perfluoropropane after pars plana vitrectomy. Arch Ophthalmol. 1989;107(5):687-691.

14. Jackson TL, Donachie PHJ, Sparrow JM, Johnston RL. United Kingdom National Ophthalmology Database Study of vitreoretinal surgery: Report 1; Case mix, complications, and cataract. Eye (Lond). 2013;27(5):644-651.

15. Ramulu PY, Do DV, Corcoran KJ, Corcoran SL, Robin AL. Use of retinal procedures in medicare beneficiaries from 1997 to 2007. Arch Ophthalmol. 2010;128(10):1335-1340.

16. Chang S, Lincoff HA, Coleman DJ, Fuchs W, Farber ME. Perfluorocarbon gases in vitreous surgery. Ophthalmology. 1985;92(5):651-656.

17. Schaefer H, Al Dwairi R, Singh P, Ohrloff C, Kohnen T, Koch F. Kann eine postoperativ beschleunigte Linsentrübung nach einer Parsplana-Vitrektomie mit Gas als Tamponade durch eine konsequente Gesicht-nach-unten-Lagerung vermieden werden? [Can postoperative accelerated lens opacification be limited by lying in "face-down position" after vitrectomy with gas as tamponade?]. Klin Monabl Augenheilkd. 2015;232(8):966-975.

\section{Dovepress}

PubMed Central and CAS, and is the official journal of The Society of Clinical Ophthalmology (SCO). The manuscript management system is completely online and includes a very quick and fair peer-review system, which is all easy to use. Visit http://www.dovepress.com/ testimonials.php to read real quotes from published authors. 